\title{
1 Impact of bioenergy crops expansion on climate-carbon cycle 2 feedbacks in overshoot scenarios
}

3 Irina Melnikova ${ }^{1,2}$, Olivier Boucher ${ }^{1}$, Patricia Cadule ${ }^{1}$, Katsumasa Tanaka ${ }^{2,3}$, Thomas Gasser ${ }^{4}$, 4 Tomohiro Hajima ${ }^{5}$, Yann Quilcaille ${ }^{6}$, Hideo Shiogama ${ }^{3}$, Roland Séférian ${ }^{7}$, Kaoru Tachiiri ${ }^{3,5}$, $5 \quad$ Nicolas Vuichard $^{2}$, Tokuta Yokohata ${ }^{3}$ and Philippe Ciais ${ }^{2}$

$6 \quad{ }^{1}$ Institut Pierre-Simon Laplace (IPSL), Sorbonne Université / CNRS, Paris, France

$7 \quad{ }^{2}$ Laboratoire des Sciences du Climat et de l'Environnement (LSCE), IPSL, Commissariat à l'énergie atomique et 8 aux énergies alternatives (CEA/ CNRS/ UVSQ), Université Paris-Saclay, Gif-sur-Yvette, France

$9 \quad{ }^{3}$ Earth System Division, National Institute for Environmental Studies (NIES), Tsukuba, Japan

$10 \quad{ }^{4}$ International Institute for Applied Systems Analysis (IIASA), Vienna, Austria

$11{ }^{5}$ Research Institute for Global Change, Japan Agency for Marine-Earth Science and Technology, Kanazawaku, 12 Japan

13 'IIASA, Vienna, Austria; now at Institute for Atmospheric and Climate Science, ETH Zürich, Switzerland

$14 \quad{ }^{7}$ CNRM, Université de Toulouse, Météo-France, CNRS, Toulouse, France

15 Correspondence to: Irina Melnikova (imelnikova@1sce.ipsl.fr) 
Table S1: DOI of simulations used by each model in this study

\begin{tabular}{|c|c|c|c|c|c|c|}
\hline ESM & & IPSL-CM6A-LR & CNRM-ESM2-1 & CanESM5 & MIROC-ES2L & UKESM1-0-LL \\
\hline \multirow[t]{4}{*}{ piControl } & $\begin{array}{l}\text { Ensemble } \\
\text { members }\end{array}$ & r1i1p1f1 & r1ilp1f2 & $\begin{array}{l}\text { r1i1p1f1, } \\
\text { r1i1p2f1 }\end{array}$ & r1i1p1f2 & $\begin{array}{c}\text { r1i1p1f2 } \\
\text { (parent to } \mathrm{r} 4 . . \text { ) }\end{array}$ \\
\hline & DOI & https://doi.org/10.2 & https://doi.org/10.2 & https://doi.org/10.2 & https://doi.org/10.2 & https://doi.org/10.2 \\
\hline & & 2033/ESGF/CMIP & 2033/ESGF/CMIP & 2033/ESGF/CMIP & 2033/ESGF/CMIP & 2033/ESGF/CMIP \\
\hline & & $\underline{6.5251}$ & $\underline{6.4165}$ & $\underline{6.3673}$ & $\underline{6.5710}$ & $\underline{6.6298}$ \\
\hline \multirow[t]{5}{*}{ historical } & $\begin{array}{l}\text { Ensemble } \\
\text { members }\end{array}$ & r1i1p1f1 & r1ilp1f2 & r1i1p1f1 & r1i1p1f2 & r4ilp1f2 \\
\hline & $\begin{array}{c}\text { Branching } \\
\text { year }\end{array}$ & 1910 & 1850 & 5201 & 1850 & 1960 \\
\hline & DOI & https://doi.org/10.2 & https://doi.org/10.2 & https://doi.org/10.2 & https://doi.org/10.2 & https://doi.org/10.2 \\
\hline & & 2033/ESGF/CMIP & 2033/ESGF/CMIP & 2033/ESGF/CMIP & 2033/ESGF/CMIP & 2033/ESGF/CMIP \\
\hline & & $\underline{6.5195}$ & $\underline{6.4068}$ & $\underline{6.3610}$ & $\underline{6.5602}$ & $\underline{6.6113}$ \\
\hline \multirow{7}{*}{$\begin{array}{l}\text { hist-noLu } \\
\quad(\text { and } \\
\text { historical)* }\end{array}$} & Ensemble & rli1p1f1 & rli1p1f2 & r1i1p1f1 & r1ilp1f2 & rli1p1f2 \\
\hline & members & r2i1p1f1 & r2i1p1f2 & r2i1p1f1 & & r2i1p1f2 \\
\hline & & r3i1p1f1 & r3i1p1f2 & r3i1p1f1 & & r3i1p1f2 \\
\hline & & r4i1p1f1 & r4i1p1f2 & r4i1p1f1 & & r4i1p1f2 \\
\hline & DOI (hist- & http://doi.org/10.22 & http://doi.org/10.22 & http://doi.org/10.22 & http://doi.org/10.22 & http://doi.org/10.22 \\
\hline & noLu) & 033/ESGF/CMIP6. & 033/ESGF/CMIP6. & 033/ESGF/CMIP6. & 033/ESGF/CMIP6. & 033/ESGF/CMIP6. \\
\hline & & $\underline{5189}$ & $\underline{4049}$ & 3602 & 5584 & $\underline{6060}$ \\
\hline \multirow[t]{5}{*}{ ssp534-over } & $\begin{array}{l}\text { Ensemble } \\
\text { members }\end{array}$ & r1ilp1f1 & r1ilp1f2 & r1ilp1f1 & r1i1p1f2 & r4ilp1f2 \\
\hline & $\begin{array}{c}\text { Branching } \\
\text { year }\end{array}$ & 2040 & 2015 & 2040 & 2015 & 2040 \\
\hline & DOI & https://doi.org/10.2 & https://doi.org/10.2 & https://doi.org/10.2 & https://doi.org/10.2 & https://doi.org/10.2 \\
\hline & & 2033/ESGF/CMIP & 2033/ESGF/CMIP & 2033/ESGF/CMIP & 2033/ESGF/CMIP & 2033/ESGF/CMIP \\
\hline & & $\underline{6.5269}$ & $\underline{6.4221}$ & $\underline{6.3694}$ & $\underline{6.5767}$ & $\underline{6.6397}$ \\
\hline \multirow[t]{5}{*}{ ssp585 } & $\begin{array}{l}\text { Ensemble } \\
\text { members }\end{array}$ & r1i1p1f1 & r1ilp1f2 & r1i1p1f1 & r1i1p1f2 & r4ilp1f2 \\
\hline & $\begin{array}{c}\text { Branching } \\
\text { year }\end{array}$ & 2015 & & 2015 & & 2015 \\
\hline & DOI & https://doi.org/10.2 & & https://doi.org/10.2 & & https://doi.org/10.2 \\
\hline & & 2033/ESGF/CMIP & & 2033/ESGF/CMIP & & 2033/ESGF/CMIP \\
\hline & & $\underline{6.5271}$ & & $\underline{6.3696}$ & & $\underline{6.6405}$ \\
\hline \multirow[t]{4}{*}{ hist-bgc } & $\begin{array}{l}\text { Ensemble } \\
\text { members }\end{array}$ & r1ilp1f1 & rlilp1f2 & r1i1p2f1 & r1i1p1f2 & r4i1p1f2 \\
\hline & $\begin{array}{c}\text { Branching } \\
\text { year }\end{array}$ & 1910 & 1850 & 5550 & 1850 & 1960 \\
\hline & DOI & & $\frac{\text { https://doi.org/10.2 }}{\underline{\text { 2033/ESGF/CMIP }}}$ & $\frac{\text { https://doi.org/10.2 }}{\text { 2033/ESGF/CMIP }}$ & $\frac{\text { https://doi.org/10.2 }}{\text { 2033/ESGF/CMIP }}$ & $\frac{\text { https://doi.org/10.2 }}{\text { 2033/ESGF/CMIP }}$ \\
\hline & & & $\underline{6.4047}$ & 6.3600 & $\underline{6.5582}$ & $\underline{6.6055}$ \\
\hline \multirow[t]{5}{*}{$\begin{array}{l}\text { ssp534- } \\
\text { over-bgc }\end{array}$} & $\begin{array}{l}\text { Ensemble } \\
\text { members }\end{array}$ & r1ilp1f1 & r1ilp1f2 & r1ilp2f1 & r1ilp1f2 & r4ilp1f2 \\
\hline & $\begin{array}{c}\text { Branching } \\
\text { year }\end{array}$ & 2040 & 2015 & 2040 & 2015 & 2040 \\
\hline & DOI & & https://doi.org/10.2 & https://doi.org/10.2 & https://doi.org/10.2 & https://doi.org/10.2 \\
\hline & & & 2033/ESGF/CMIP & 2033/ESGF/CMIP & 2033/ESGF/CMIP & 2033/ESGF/CMIP \\
\hline & & & $\underline{6.4223}$ & $\underline{6.3695}$ & $\underline{6.5769}$ & $\underline{6.6401}$ \\
\hline \multirow[t]{4}{*}{ ssp585-bgc } & $\begin{array}{l}\text { Ensemble } \\
\text { members }\end{array}$ & r1i1p1f1 & r1ilp1f2 & r1i1p2f1 & r1i1p1f2 & r4ilp1f2 \\
\hline & $\begin{array}{c}\text { Branching } \\
\text { year }\end{array}$ & 2015 & & 2015 & & 2015 \\
\hline & DOI & & & $\frac{\text { https://doi.org/10.2 }}{\text { 2033/ESGF/CMIP }}$ & & $\frac{\text { https://doi.org/10.2 }}{\text { 2033/ESGF/CMIP }}$ \\
\hline & & & & 6.3697 & & 6.6409 \\
\hline
\end{tabular}

*While one ensemble member of historical simulations is used for the analysis, we use an ensemble mean of all available ensemble members to evaluate the historical LUC emissions. 
Table S2: Carbon-concentration $\beta\left(\mathrm{GtC}_{\mathrm{ppm}}{ }^{-1}\right)$ and carbon-climate $\gamma\left(\mathrm{GtC}^{\circ} \mathrm{C}^{-1}\right)$ feedback parameters estimated by three approaches and five ESMs, averaged over 2090-2100 under SSP5-3.4-OS pathway.

\begin{tabular}{|c|c|c|c|c|c|}
\hline & IPSL-CM6A-LR & CNRM-ESM2-1 & CanESM5 & MIROC-ES2L & UKESM1-0-LL \\
\hline Global $\beta\left(\mathrm{GtC} \mathrm{ppm}^{-1}\right)$ & 1.24 & 3.96 & 1.66 & 1.65 & 1.14 \\
\hline$\beta$ LUC (fLuc) & -0.62 & -0.69 & & & \\
\hline$\beta$ noLUC (fLuc) & 1.86 & 3.87 & & & \\
\hline$\beta$ LUC (crop threshold) & 0.07 & 0.55 & -0.38 & -0.08 & 0.09 \\
\hline$\beta$ noLUC (crop threshold) & 1.17 & 2.63 & 1.21 & 1.01 & 1.59 \\
\hline$\beta$ LUC (two sim-ns since 1850) & -1.23 & & & -0.63 & \\
\hline$\beta$ noLUC (two sim-ns since 1850 ) & 2.48 & & & 2.30 & \\
\hline$\beta$ LUC (two sim-ns since 2040) & -0.13 & & & & \\
\hline$\beta$ noLUC (two sim-ns since 2040) & 1.37 & & & & \\
\hline Global $\gamma\left(\mathrm{GtC}^{\circ} \mathrm{C}^{-1}\right)$ & -18.45 & -114.30 & -36.96 & -99.33 & -52.32 \\
\hline$\gamma$ LUC (fLuc) & 0.82 & 0.64 & & & \\
\hline$\gamma$ noLUC (fLuc) & -10.32 & -94.32 & & & \\
\hline$\gamma$ LUC (crop threshold) & -1.50 & -22.08 & -4.62 & -4.36 & -16.67 \\
\hline$\gamma$ noLUC (crop threshold) & -7.96 & -71.63 & -11.62 & -31.15 & -75.99 \\
\hline$\gamma$ LUC (two sim-ns since 1850) & -5.33 & & & -17.41 & \\
\hline$\gamma$ noLUC (two sim-ns since 1850) & -13.12 & & & -69.08 & \\
\hline$\gamma$ LUC (two sim-ns since 2040) & 2.22 & & & & \\
\hline$\gamma$ noLUC (two sim-ns since 2040) & -69.08 & & & & \\
\hline
\end{tabular}

Table S3: Carbon-concentration $\beta\left(\mathrm{GtC}_{\mathrm{ppm}}{ }^{-1}\right)$ and carbon-climate $\gamma\left(\mathrm{GtC}^{\circ} \mathrm{C}^{-1}\right)$ feedback parameters mean values estimated by three approaches and five ESMs averaged over 2090-2100 under SSP5-3.4-OS pathway (the values of IPSL-CM6A-LR and CNRM-ESM2-1 by cropland threshold approach, and IPSL-CM6A-LR by two simulations since 2040 approach are excluded).

\begin{tabular}{lccc}
\hline & Mean & SD & $\begin{array}{c}\text { Cumulative contribution } \\
\text { over 2000-2100 }(\mathrm{GtC})\end{array}$ \\
\hline Global $\beta\left(\mathrm{GtC} \mathrm{ppm}^{-1}\right)$ & 1.93 & 1.16 & $-42.55 \pm 41.08$ \\
$\beta$ LUC & -0.51 & 0.44 & $349.56 \pm 129.43$ \\
$\beta$ noLUC & 2.05 & 0.97 & $-13.00 \pm 12.27$ \\
Global $\gamma\left(\mathrm{GtC}^{\circ} \mathrm{C}^{-1}\right)$ & -64.27 & 40.99 & $-88.97 \pm 76.83$ \\
$\gamma$ LUC & -6.70 & 7.49 & 35.32 \\
$\gamma$ noLUC & -43.66 & & \\
\hline
\end{tabular}


a)

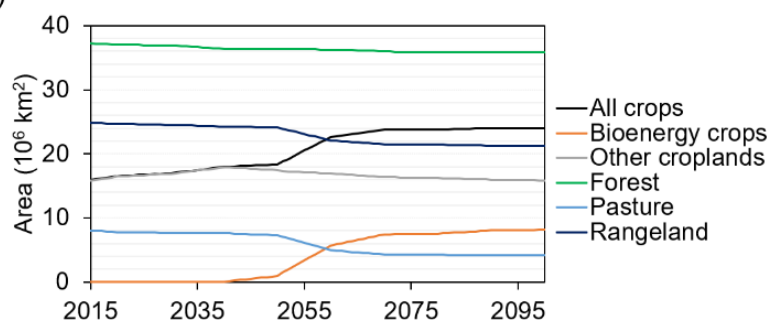

b)

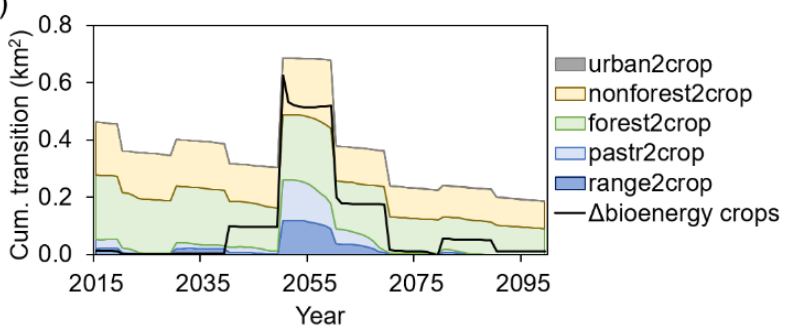

c)

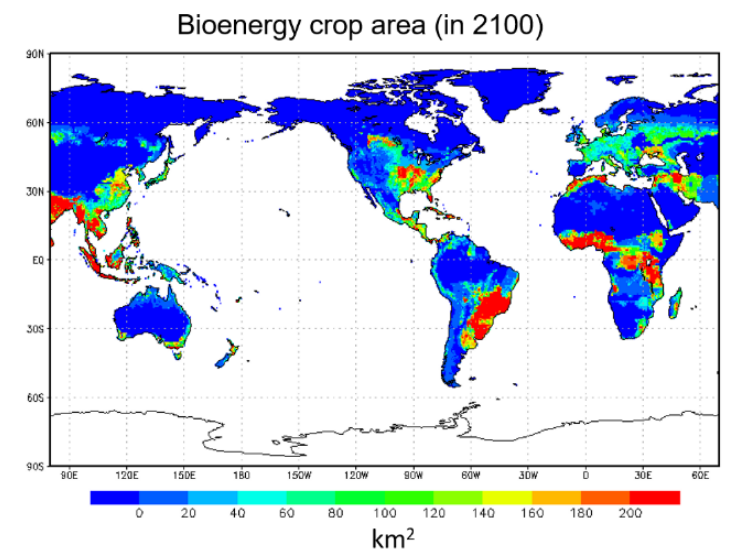

d) Forest area $(2100-2040)$

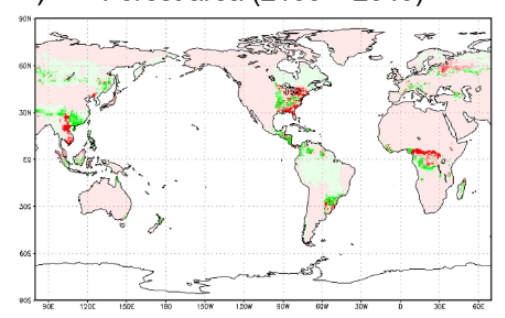

e) Pasture area (2100 - 2040)

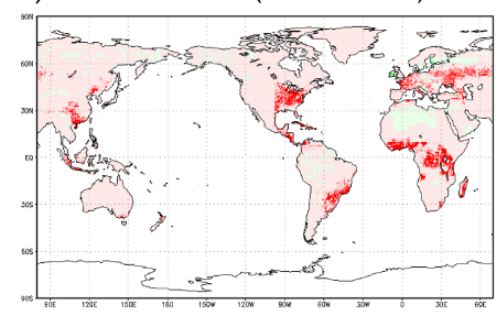

f) Crop area $(2100-2040)$

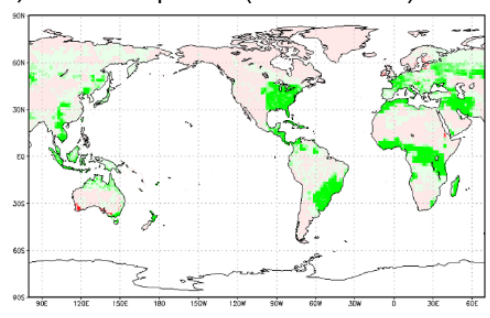

Figure S1: Time series of the changes in the global area of (a) land states, including bioenergy crops, and (b) cumulative transitions, including transitions of rangeland to crop (range2crop), pasture to crop (pastr2crop), primary and secondary forest to crop (forest2crop), primary and secondary non-forest to crop (nonforest2crop), urban area to crop (urban2crop), and yearly change rate of bioenergy crops ( $\Delta$ bioenergy crops) in 2015-2100 by LUH2. Here the cumulative transitions are given for reference, they are not absolute because they do not include transitions from crops to other states. Panel (c) shows the spatial variation of the bioenergy crops in 2100, (d) the difference in the area of forest, (e) pastures, and (f) croplands in years 2100 and 2040 given by LUH2. 

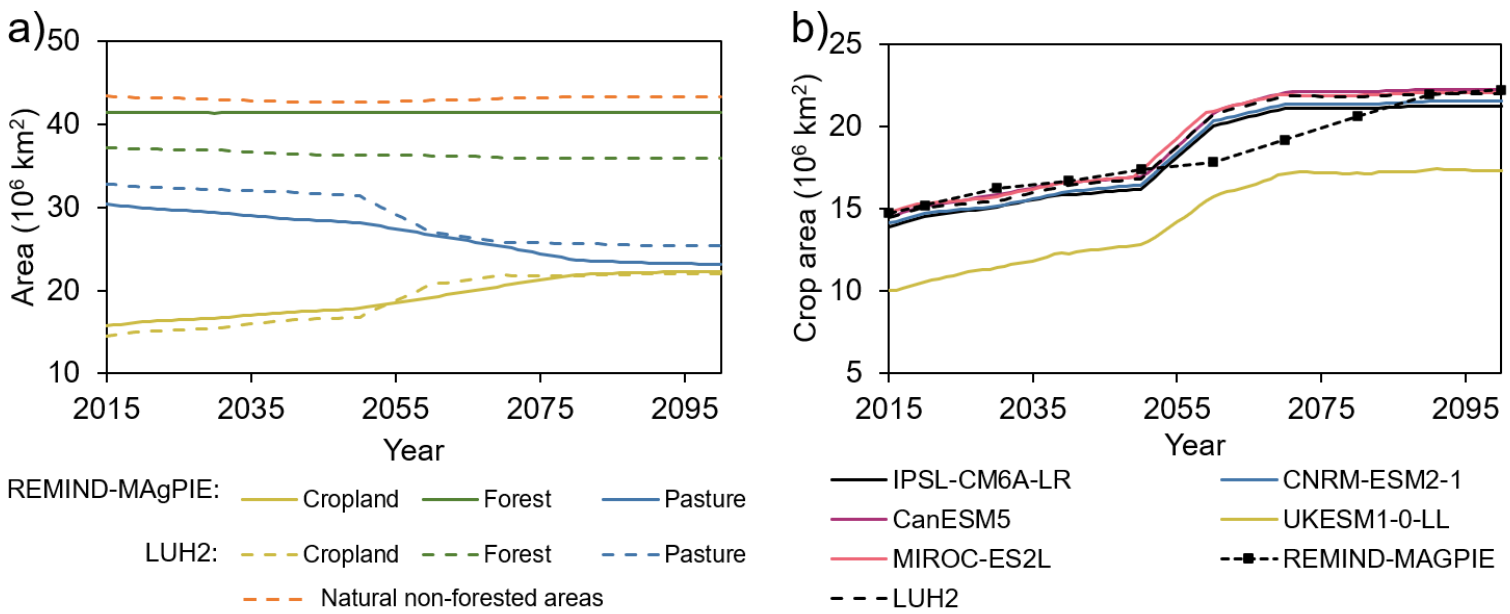

REMIND-MAgPIE:

Cropland — Forest

- Pasture

LUH2: - - -Cropland - - -Forest - - -Pasture

- - - Natural non-forested areas

$---\mathrm{LUH} 2$

Figure S2: Time series of (a) the changes in the area of croplands, pastures, and forests according to REMIND-MAgPIE (solid lines) and LUH2 (dashed lines) and (b) the area of croplands as prescribed in LUH2 and implemented in REMIND-MAgPIE and five CMIP6 ESMs in 2015-2100 under SSP5-3.4-OS pathway. In panel (a), pastures and rangelands of LUH2 are treated together as pastures; and forest represents the sum of primary forested land and potentially forested secondary land. The croplands of LUH2 include C3, C4 annual crops, C3, C4 perennial crops, and C3 nitrogen-fixing crops. The natural non-forested areas (that include non-forested primary land and potentially nonforested secondary land) of LUH2 are shown for reference. 

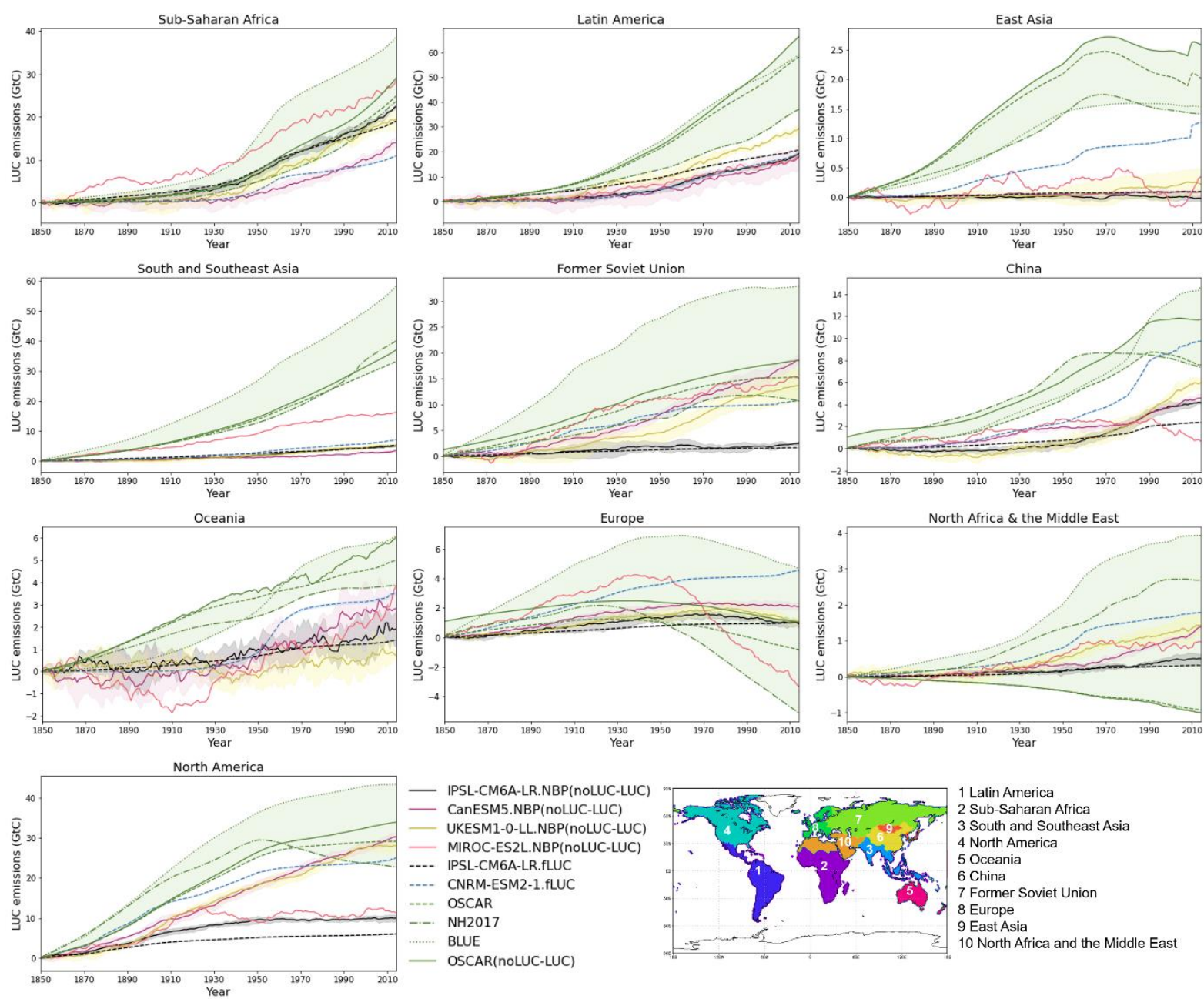

Figure S3: Evaluation of cumulative regional LUC emissions by ESMs against three bookkeeping models. LUC emissions are defined by two methods: 1 ) the difference in NBP between simulations with and without LUC (solid lines) and 2) the "fLuc" variable provided in CMIP6 (dashed lines). The estimates of the bookkeeping approach using OSCAR are shown for cases with (noLUC-LUC) and without LASC). The range of bookkeeping models is in shaded green. 
a) Global (mean):
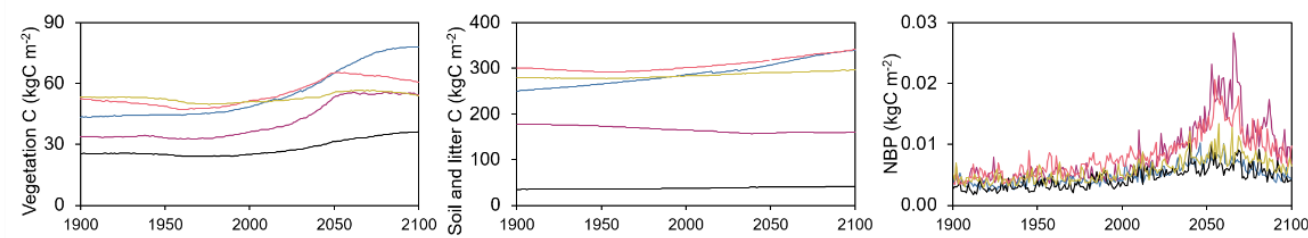

b) Crop-concentrated areas of the year 2100 (mean):
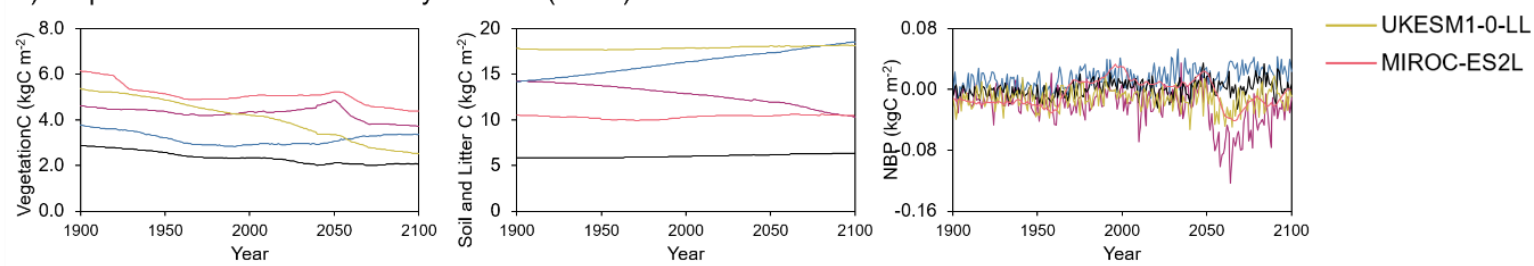

60

66

Figure S4: Time series of changes in vegetation and soil, including litter, carbon pools, and NBP (a) globally and (b) in crop-concentrated areas as defined via the "cropland threshold" approach by CMIP6 ESMs. The changes in NBP are given as 10-year moving averages.
Cum. $\triangle$ NBP in crop-concentrated areas
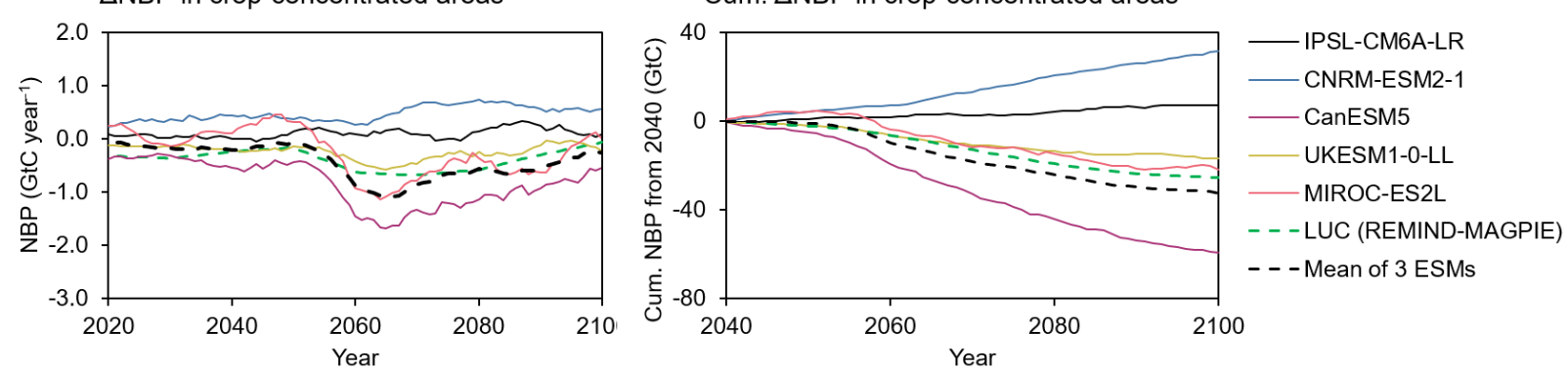

Figure S5: Time series of LUC emissions (left) and cumulative LUC emissions from the year 2040 (right) estimates by CMIP6 ESMs via the "cropland threshold" approach and from REMIND-MAgPIE as given in the IIASA database. $\triangle N B P$ refers to the change in NBP in crop-concentrated areas relative to piControl. The mean of three ESMs is calculated using CanESM5, UKESM1-0-LL, and MIROC-ES2L. Positive is sink to the land. 

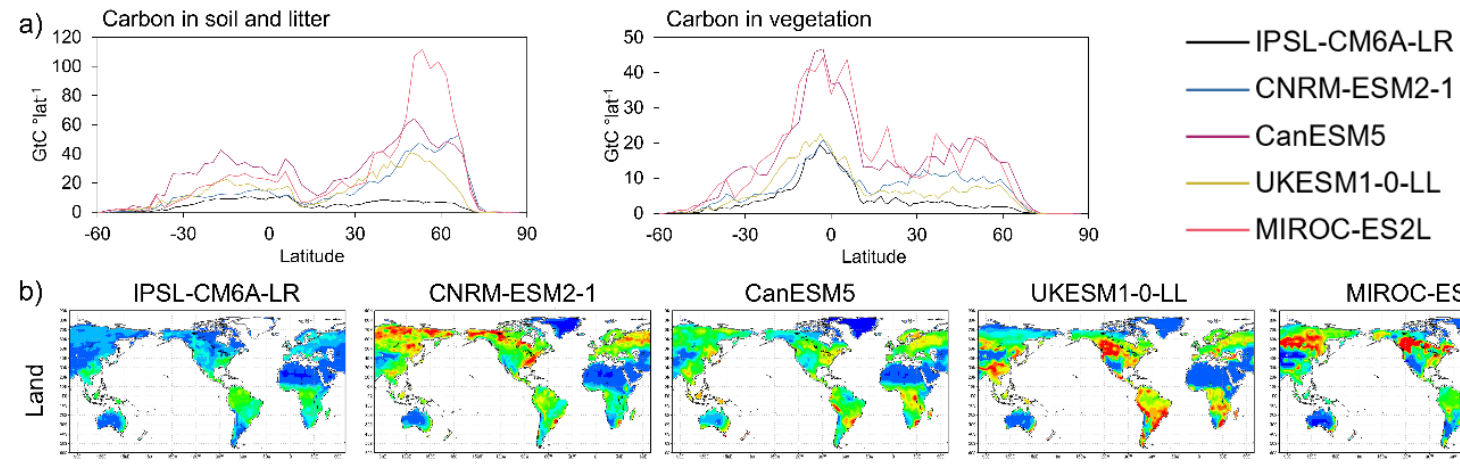

CNRM-ESM2-1

CanESM5

UKESM1-0-LL

MIROC-ES2L
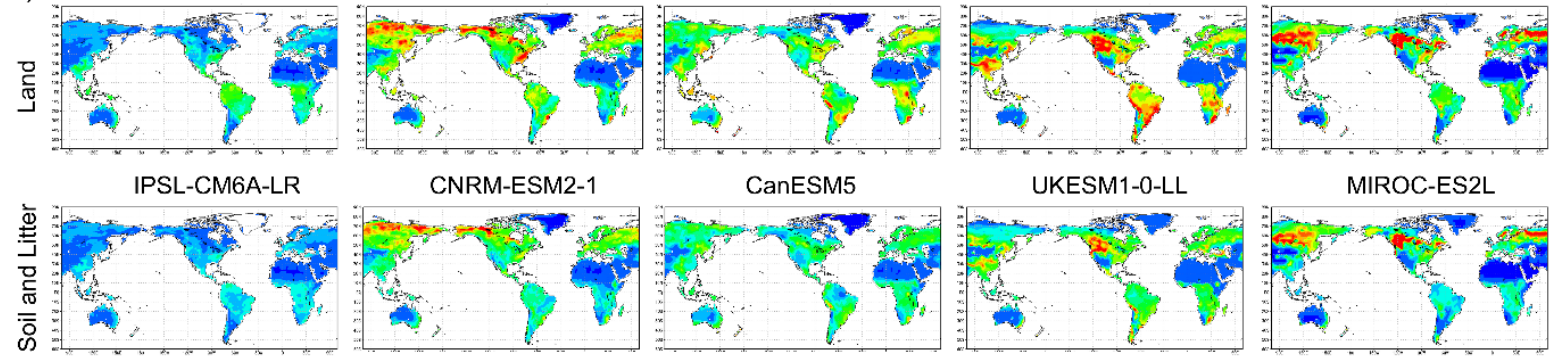

CNRM-ESM2-1

CanESM5

UKESM1-0-LL

MIROC-ES2L
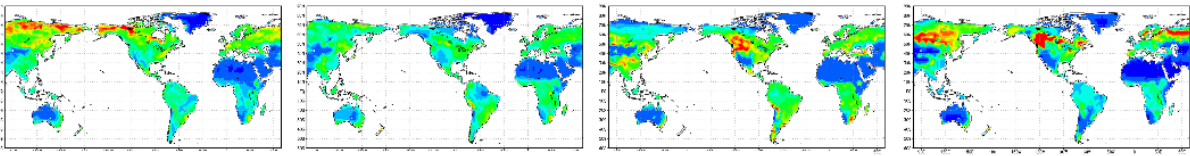

$\begin{array}{lllll}0 & 4 & 8 & 12 & 16 \mathrm{~kg} \mathrm{C} \mathrm{m}^{-2} \\ & & & { }^{24}\end{array}$

IPSL-CM6A-LR

CNRM-ESM2-1

CanESM5

UKESM1-0-LL

MIROC-ES2L

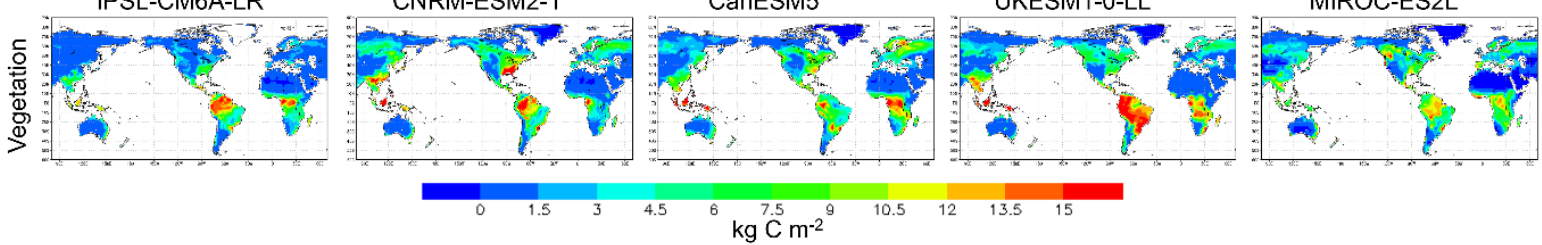

Figure S6: (a) Latitudinal and (b) spatial distributions of the land (soil, including litter, and vegetation) carbon pools

in piControl in the five CMIP6 ESMs used in this study. 
a) Crop-concentrated areas:
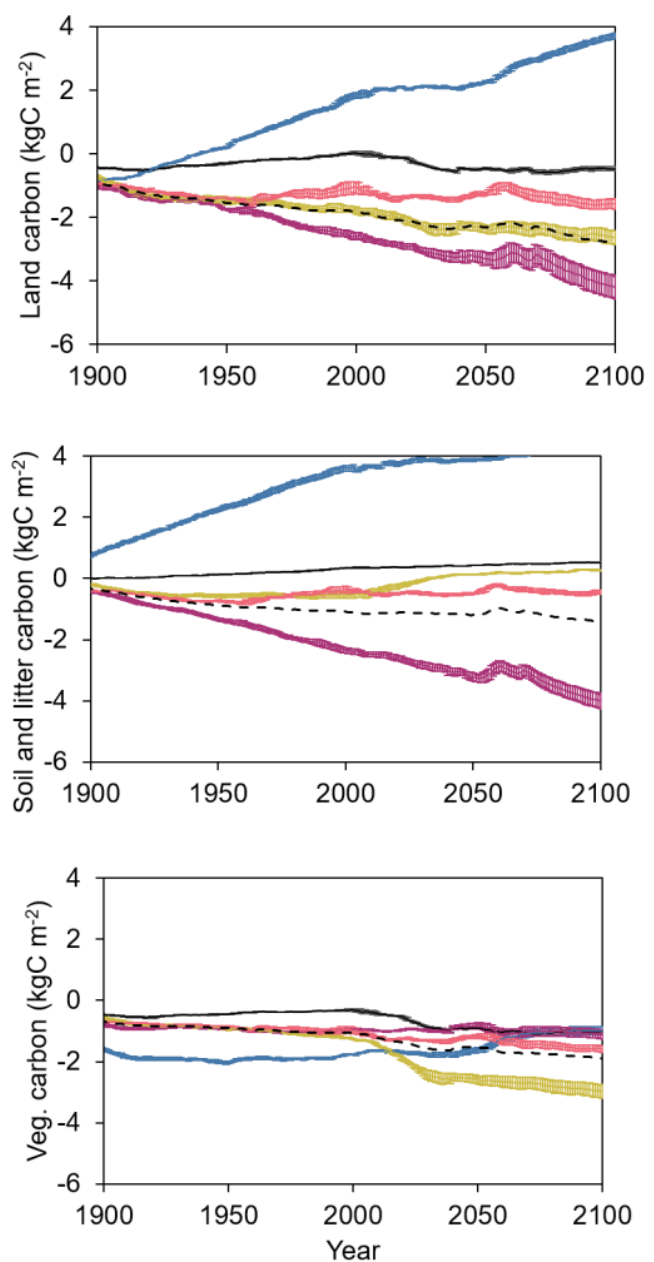

a) No-crop areas:
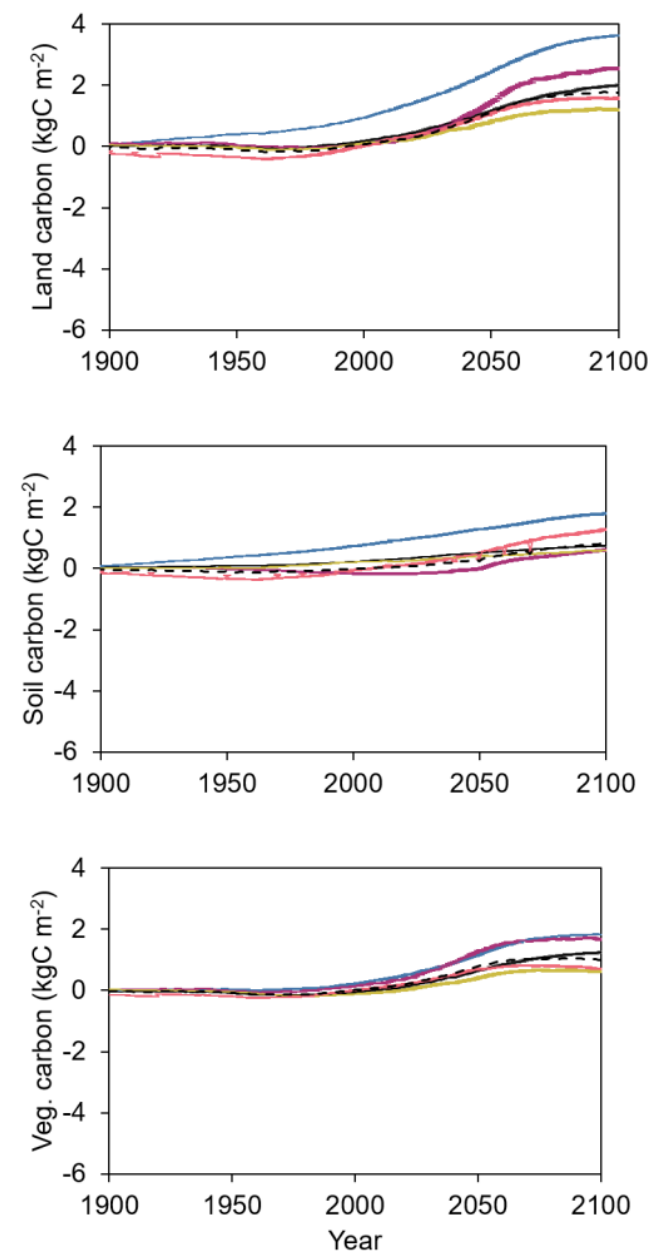

-IPSL-CM6A-LR -CNRM-ESM2-1 - CanESM5

-.-Mean of 3 ESMs

Figure S7: Time series of the spatial mean changes in the land carbon pool and its components, soil, including litter, and vegetation pools, in crop-concentrated and no-crop areas. The mean of three ESMs is calculated using CanESM5, UKESM1-0-LL, and MIROC-ES2L. 
a) LUH2 biofuel crop area

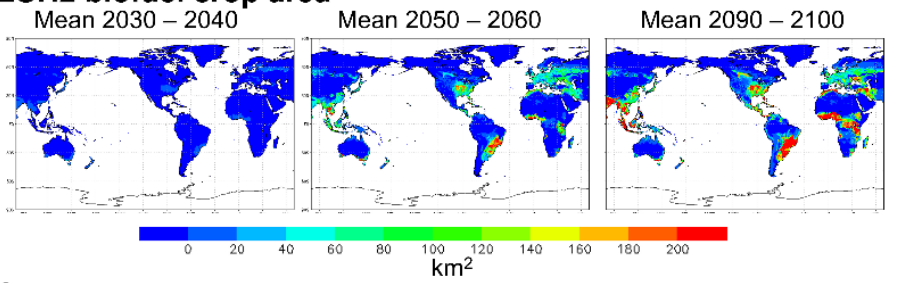

b) $\boldsymbol{\beta}$
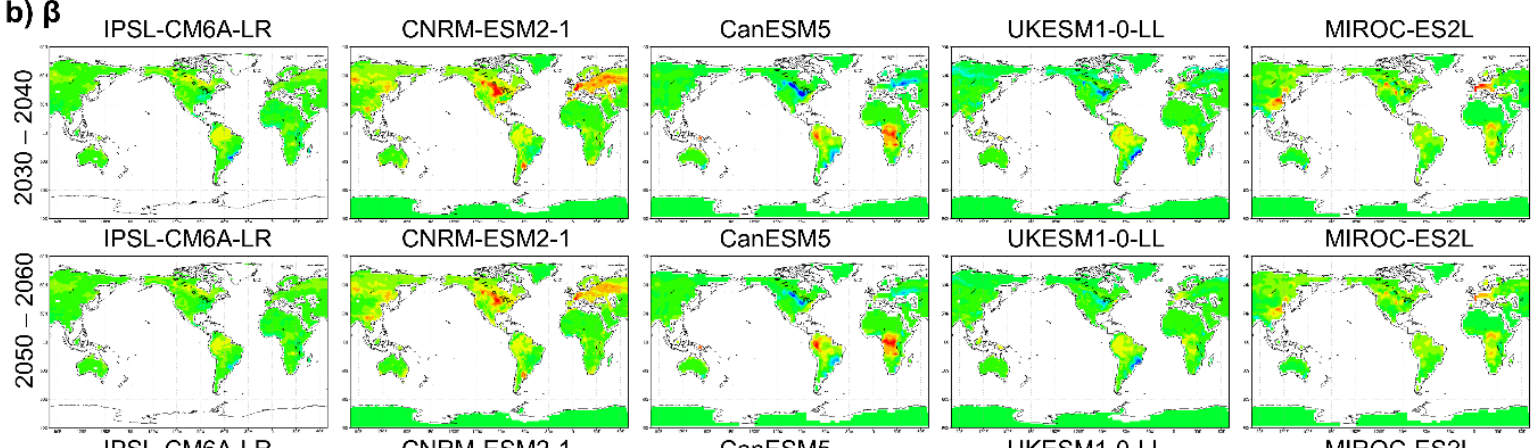

UKESM1-0-LL

MIROC-ES2L

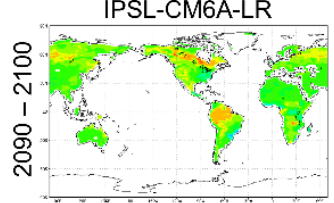

CNRM-ESM2-1
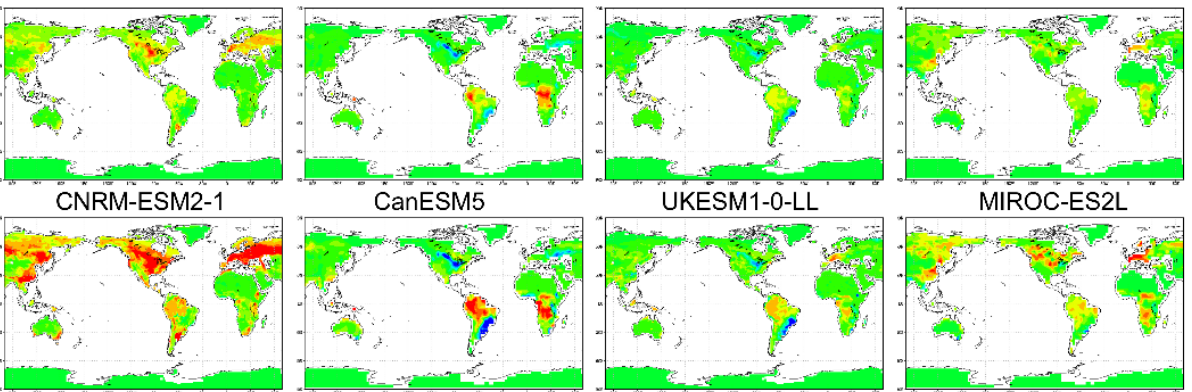

UKESM1-0-LL

MIROC-ES2L
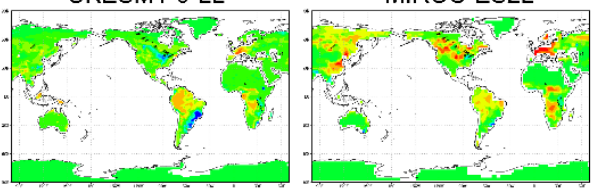

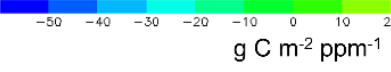

c) Y IPSL-CM6A-LR

CNRM-ESM2-1
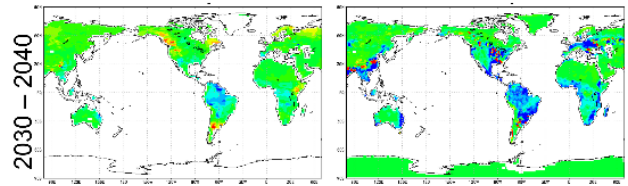

CanESM5

UKESM1-0-LL

MIROC-ES2L
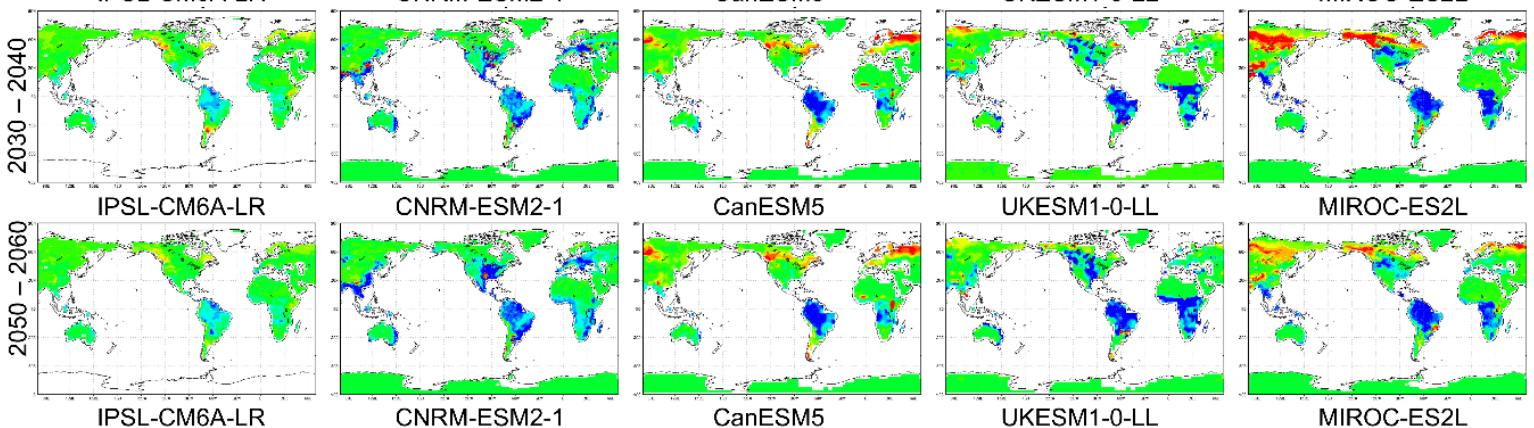

UKESM1-0-LL

MIROC-ES2L
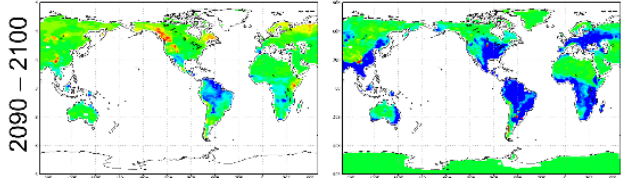

CanESM5
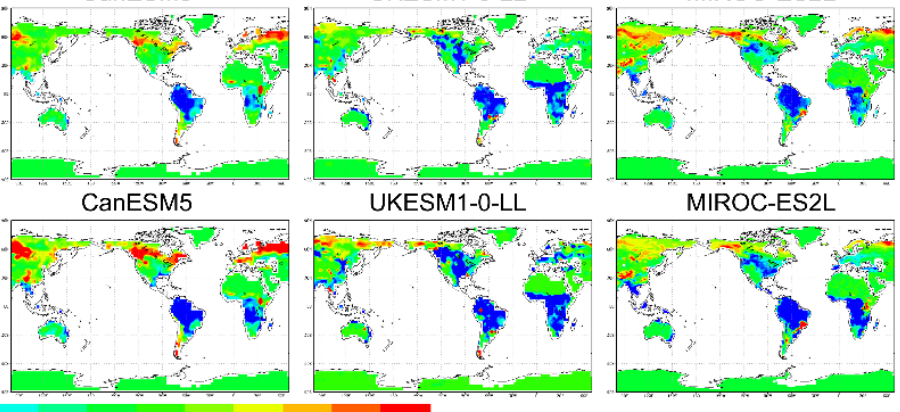

$\mathrm{g} \mathrm{C} \mathrm{m}^{-2}{ }^{\circ} \mathrm{C}^{-1}$

Figure S8: (a) The second-generation biofuel cropland area given in LUH2, the spatial variation of (b) $\beta$ and (c) $\gamma$ parameters by five ESMs given as a decadal mean for the 2030s, 2040s, and 2090s. 
a) MIROC-ES2L
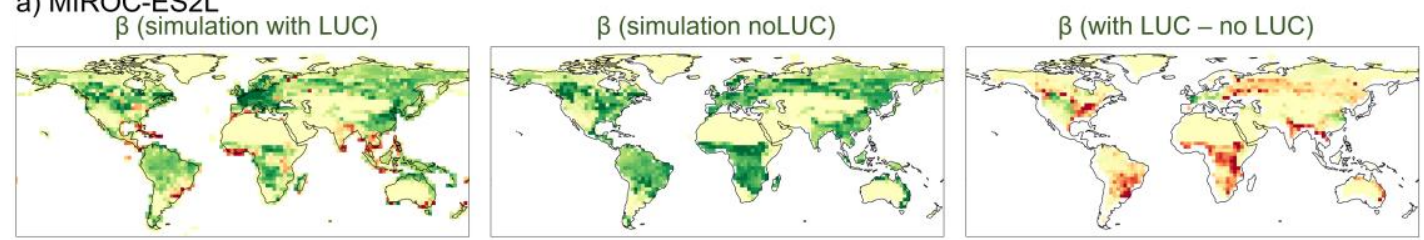

Y (simulation with LUC)

Y (simulation noLUC)
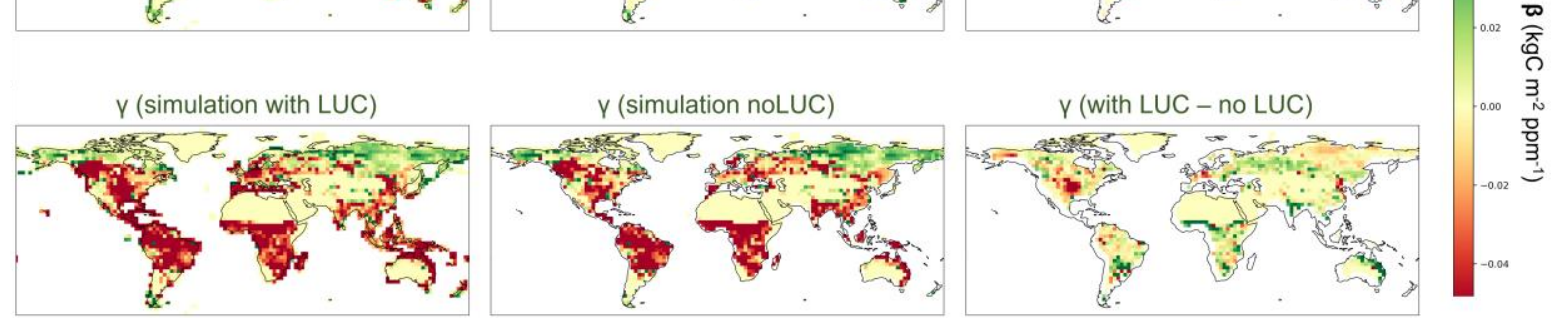

b) IPSL-CM6A-LR

$\beta$ (simulation with LUC)
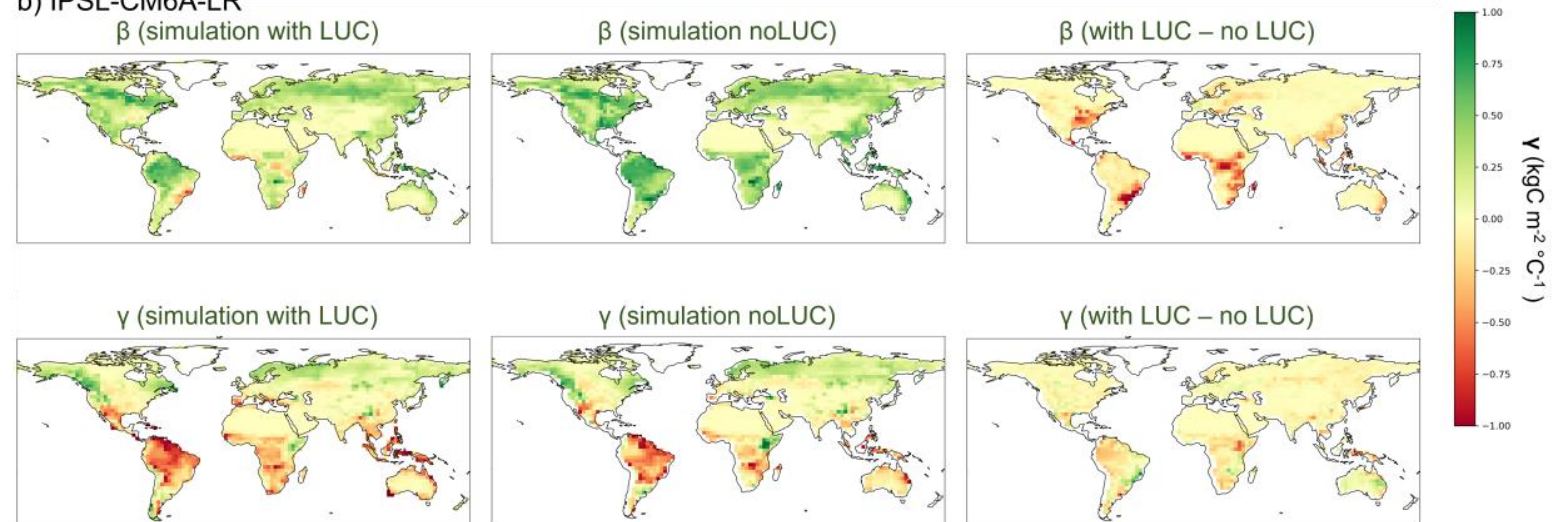

Y (simulation with LUC)

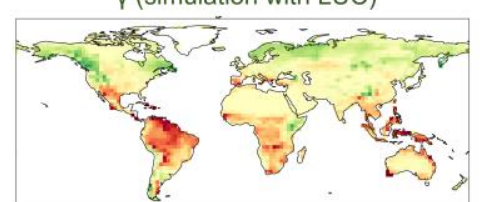

Y (simulation noLUC)
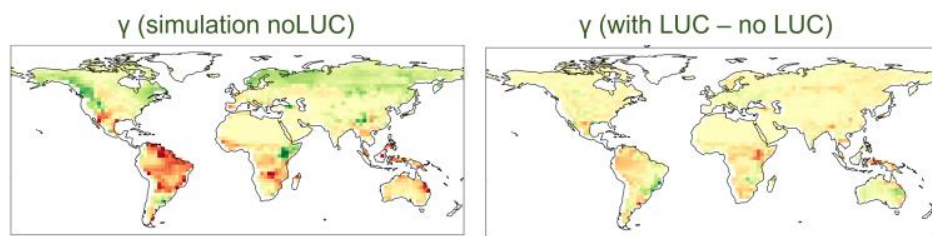

Figure S9: Spatial distributions of the of $\beta$ and $\gamma$ parameters by (a) MIROC-ES2L and (b) IPSL-CM6A-LR given as a 2090-2100 decadal means in simulations with and without LUC, and their difference. The negative values indicate less sink or more source from land to atmosphere. 
a) IPSL-CM6A-LR

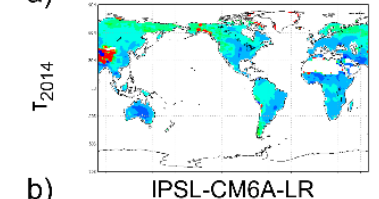

b)
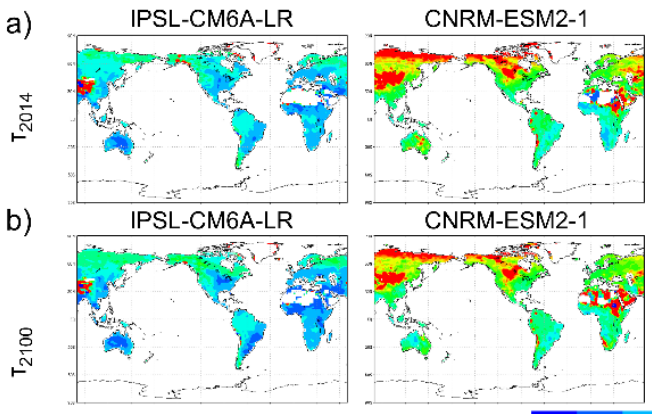

CNRM-ESM2-1
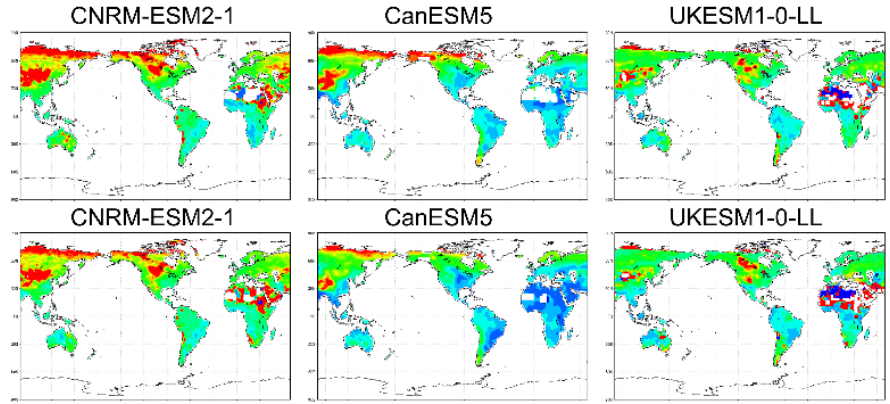

UKESM1-0-LL
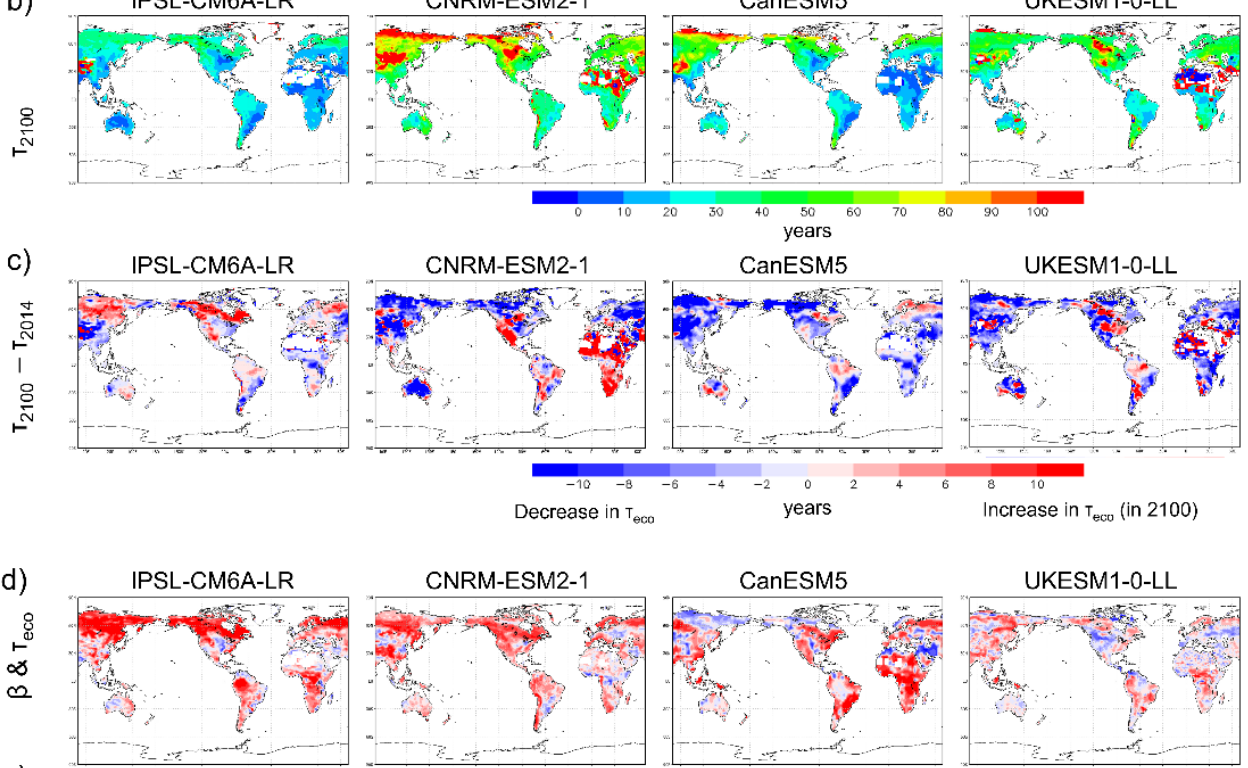

e)
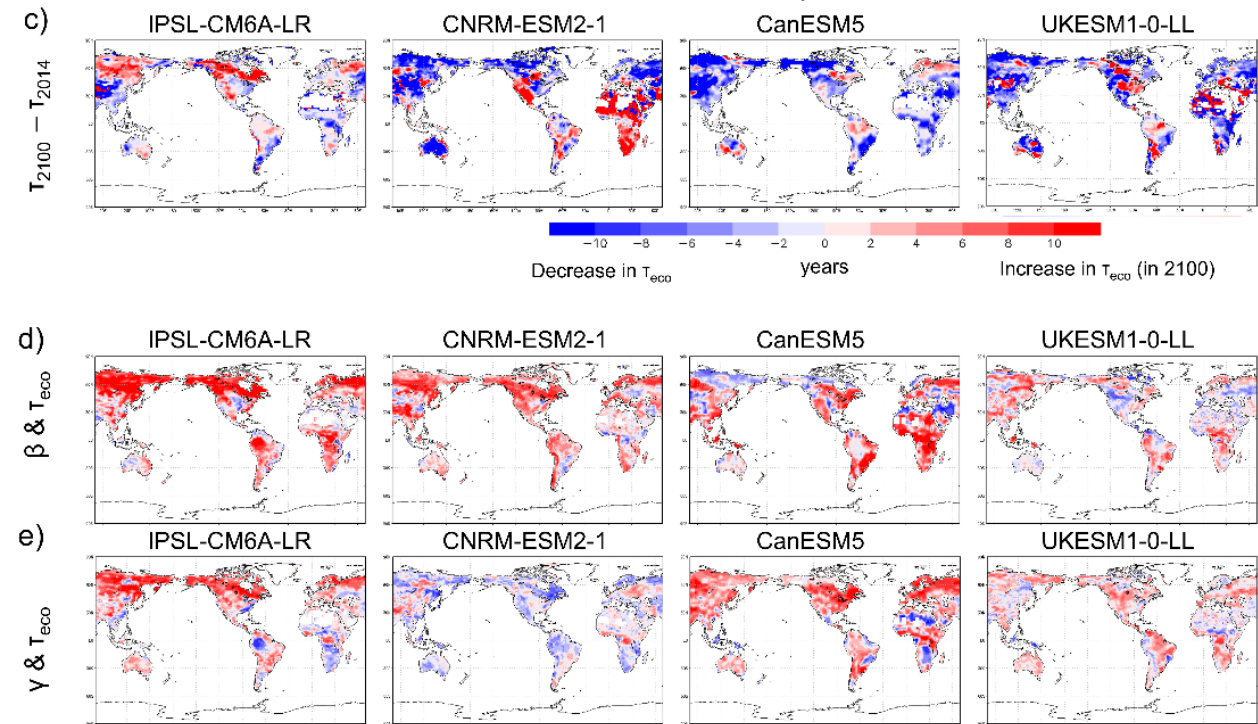

UKESM1-0-LL

CanESM5

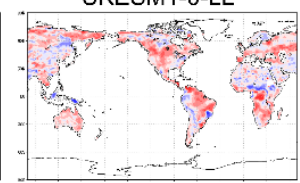

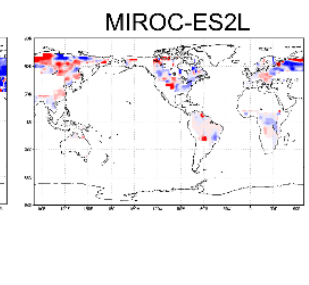
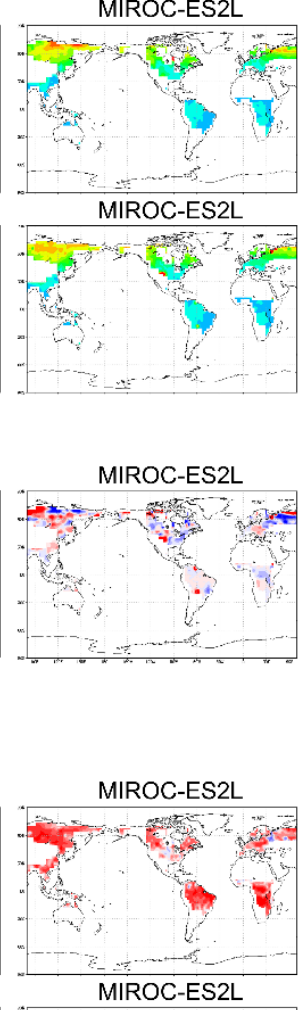

MIROC-ES2L
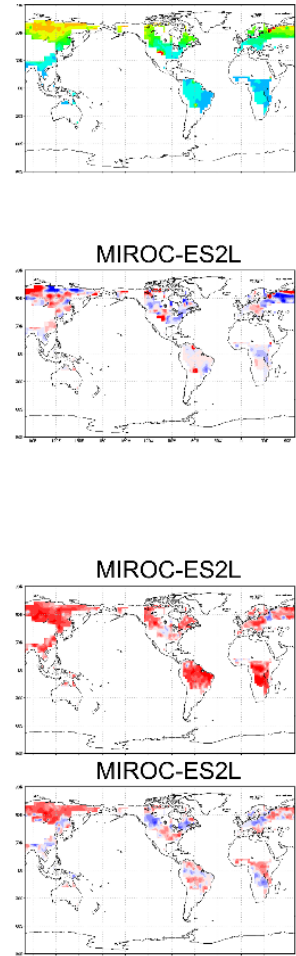

Correlation coefficient

Figure S10: Spatial distributions of the carbon turnover time $\tau_{\text {eco }}$ in the years (a) 2014 and (b) 2100, and the difference in $\tau_{\text {eco }}$ between years 2100 and 2014 (the negative values indicate a decrease in $\tau_{\text {eco }}$ in 2100 from 2014 levels). The decrease in $\tau_{\text {eco }}$ indicates acceleration of carbon turnover. The correlation coefficients between $\tau_{\text {eco }}$ and (d) $\beta$ and (e) $\gamma$ feedback parameters that are estimated for the $2040-2100$ period. The colormap is limited for MIROC-ES2L in the areas, where NPP is nearly zero and is also partly attributed to a relatively low spatial resolution of the model. 